\title{
'Weeds of Our Own Making': Language Ideologies, Swearing and the Criminal Law
}

\author{
Elyse Methven
}

\begin{abstract}
In adjudicating offensiveness, judicial officers create and apply a number of 'common sense' judgments about how language works. These 'language ideologies' are rarely informed by, and are often contrary to, empirical research and linguistic literature; they are instead constructed through constant repetition of popular views and questionable assumptions. Through the cases Jolly $v$ The Queen and Heanes $v$ Herangi, this article examines how judicial officers construct realities about swear words in the criminal law. In the first part, I briefly set out the legal doctrine in relation to offensive language crimes. Following this, I draw on critical discourse analysis to critique language ideologies in offensive language cases. I argue that offensive language crimes, as they are currently framed and interpreted, encourage judicial officers to pick and choose from whichever linguistic or 'folk-linguistic' ideas they see fit, and enable them to elude the rigorous critiques to which linguists are exposed.
\end{abstract}

\section{INTRODUCTION}

In the early hours of 9 December 2007, police arrived at Schiller Place, Emerton, where a large street brawl was taking place. Rebecca Smith, the fiancée of Sean Graham Jolly, had been injured in the brawl and was lying on the roadway. After police made various attempts to control the situation and to attend to Smith, Jolly - concerned about the welfare of his fiancée, intoxicated and affected by capsicum spray - approached the officers in an aggressive manner. Jolly said to Constable Giles, 'Take your gun off, you low fuck, before I belt the fuck out of you'. In response to a police command, a police dog bit Jolly, causing him significant injury to his neck. While waiting for an ambulance, Jolly told the police officers, 'You are fucking dog cunts. You fucked his mum and he fucked your mum and he fucked his mum and his sister and your brother and son'; and 'Fuck off you dog cunts. You fucked his mum and he fucked yours'. ${ }^{1}$

* This essay is derived from doctrinal research undertaken at the Faculty of Law, University of Technology Sydney. The author would like to express her gratitude for the ongoing advice of her PhD supervisors, Professor Katherine Biber, Associate Professor Penny Crofts and Associate Professor Thalia Anthony. The author would also like to thank Dr Diana Eades for her helpful comments.

1 Jolly $v$ The Queen [2009] NSWDC 212. Constable Hauver gave evidence that after he had admonished Jolly, Jolly replied, 'Get fucked. You, I'm going to sue 
Jolly was charged and convicted of a number of offences, including using offensive language in a public place contrary to $\mathrm{s} 4 \mathrm{~A}(1)$ of the Summary Offences Act 1988 (NSW) (SO Act). When Jolly appealed his convictions to the District Court of New South Wales, Cogswell DCJ considered whether Jolly's words amounted to offensive language or whether he had a 'reasonable excuse'2 for their use. Cogswell DCJ stated:

$[\mathrm{T}] \mathrm{o}$ my mind the language when it went on to make references to members of the police officers' families having sexual relations with each other was no longer such that it allowed Mr Jolly a defence under the section. I have the same view about the reference to animals in the expression 'Dog cunts'. The images conjured up by such language are obviously - in my opinion very offensive to anyone who might overhear them. ${ }^{3}$

Cogswell DCJ ultimately dismissed the appeal, stating, 'Parliament has elected to keep this particular offence on the statute book and I regard the words used by Mr Jolly as amounting to offensive language both before and after he was bitten by the dog'. ${ }^{4}$

In this essay, I examine language ideologies - 'common sense' judgments about how language works - in judicial discourse on offensive language. ${ }^{5}$ To begin, I briefly set out the legal doctrine in relation to offensive language crimes. Following this, I elaborate on the concept of language ideologies, drawing on the work of sociolinguist Diana Eades, and relate this to the subject of swearing. I employ these ideas, as well as the critical discourse analysis work of Theo van Leeuwen and Norman Fairclough to critique a number of 'common sense' ideas about swearing in offensive language cases. ${ }^{6}$ I use the term 'discourse', as set out in the writings of Michel Foucault, to refer to socially constructed ways of knowing some aspect of reality. ${ }^{7}$ I focus on how judicial officers, through discourse, construct realities about swear words that have become naturalised within criminal law. I argue that offensive language crimes, as they are currently framed and interpreted, enable and indeed encourage judicial officers to pick and choose from whichever linguistic or 'folk-linguistic' ideas they see

you, you cunt. You let the fucking dog bite me and didn't pull it off. You can get fucked'.

The defence of 'reasonable excuse', contained in s 4A(2) of the SO Act (NSW), provides that it is a sufficient defence to a prosecution for an offence under s $4 \mathrm{~A}(1)$ if the defendant satisfies the court that the defendant had a reasonable excuse for conducting himself or herself in the manner alleged in the information for the offence. Jolly $v$ The Queen [2009] NSWDC 212, [22].

4 Ibid.

$5 \quad$ Diana Eades, Sociolinguistics and the Legal Process (Channel View Books, 2010) 241.

6 Theo van Leeuwen, Discourse and Practice: New Tools for Critical Discourse Analysis (Oxford University Press, 2008); Norman Fairclough, Language and Power (Longman, 1989); Norman Fairclough, Discourse and Social Change (Polity Press, 1992).

7 Theo Van Leeuwen, 'Discourse as the Recontextualization of Social Practice: A Guide' in Ruth Wodak and Michael Meyer (eds), Methods of Critical Discourse Analysis (Sage, 2009) 144, 144, citing Michel Foucault, The Order of Things: An Archaelogy of the Human Sciences (Tavistock Publications, 1970). 
fit, without subjecting their statements to the kinds of rigorous critique to which many linguists are themselves exposed.

\section{Offensive Language Crimes}

The crime with which Jolly was charged and convicted is one of a number of 'offensive language crimes' that exist across Australia: laws that prohibit the use of offensive, insulting, indecent or obscene language in or near, or within hearing from, a public place. ${ }^{8}$ Each of these adjectives - offensive, insulting, obscene and so forth - is not defined in statute, but has acquired a distinct meaning through case law. The oft-cited definition of offensive is 'such as is calculated to wound the feelings, arouse anger or resentment or disgust or outrage in the mind of a reasonable person', ${ }^{9}$ whereas words are considered obscene or indecent if they are highly offensive to recognised standards of common propriety. ${ }^{10}$

There is no prescriptive list of offensive words; instead language must be assessed in light of the context in which it was used. ${ }^{11}$ In considering 'the context' a decision-maker might take a number of factors into account, including: the location and time at which the language was used; who was likely to be in the vicinity; who was actually in the vicinity; whether the defendant was intoxicated; whether the language was said to a person in a position of 'authority'; whether the utterance may have had special relevance to the recipient; the tone, volume or 'vehemence' of the utterance; and any mannerisms accompanying the language used. ${ }^{12}$

The test as to whether language is offensive, obscene or indecent is an objective one, although jurisdictions differ on their application of the perspective of 'the reasonable person', 'contemporary community standards', or an amalgamation of both perspectives. ${ }^{13}$ Jurisdictions such as the Northern Territory and South Australia have taken divergent approaches as to whether offensive language crimes incorporate, or should incorporate,

8 See, for example, Summary Offences Act 2005 (Qld) s 6; Summary Offences Act 1953 (SA) s 7(1)(a); Police Offences Act 1935 (Tas) s 12; Summary Offences Act 1966 (Vic) s 17(1)(c); Criminal Code (WA) s 74A; Crimes Act 1900 (ACT) s 392; Summary Offences Act 1978 (NT) s 47 and s 53.

$9 \quad$ Worcester $v$ Smith [1951] VLR 316, 318 (O'Bryan J).

10 Robertson v Samuels (1973) 4 SASR 465, 473-474 (Hogarth J); Gul v Informant Sen Cons A Creed [2010] VSC 185. For example, the Supreme Court of Victoria held that the phrase 'fucking bitch', used by Ms Gul when accused of ingesting an (allegedly stolen) Easter egg in Big W, was indecent pursuant to s 17 of the Summary Offences Act 1966 (Vic).

11 Gul v Informant Sen Cons A Creed [2010] VSC 185; Hortin v Rowbottom (1993) 68 A Crim R 381; Edbrooke v Hartman [1991] QDC 15, 5 (Wylie QC, DO).

12 Green v Ashton [2006] QDC 8; Spence v Loguch (unreported, NSWSC, Sully J, 12 November 1991); Heanes v Herangi (2007) 175 A Crim R 175; Hortin v Rowbottom (1993) 68 A Crim R 381.

13 See, for example, Del Vecchio v Couchy [2002] QCA 9; Heanes v Herangi (2007) 175 A Crim R 175; Douglas Conners v Craigie (unreported, NSWSC, McInerney J, 5 July 1993); Bills v Brown [1974] Tas SR (NC) N13; Ball v McIntyre (1966) 9 FLR 237; Worcester v Smith [1951] VLR 316; Police v Butler [2003] NSWLC 2. 
a mental element, and if so, what that element entails. ${ }^{14}$ In New South Wales, criminal law scholars McNamara and Quilter have persuasively argued that s $4 \mathrm{~A}$ of the $S O$ Act should incorporate intention to offend as an element, though we await an appellate decision to resolve this issue. ${ }^{15}$

There are stark disparities in punishments for offensive language crimes, ranging from a fine of $\$ 660$ in New South Wales to up to six months' imprisonment in Queensland and the Northern Territory. ${ }^{16}$ In New South Wales, the Northern Territory, Queensland, Tasmania, Victoria and Western Australia, police have the additional option to issue criminal infringement notices ('CINs' or 'on-the-spot fines') for offensive language crimes. ${ }^{17} \mathrm{CINs}$ are notices to the effect that if the person served does not wish to have the matter determined by a court, that person must pay the prescribed amount within a fixed time period. Fines range from $\$ 110$ in Queensland to $\$ 500$ in New South Wales and Western Australia. In 2014, the Northern Territory Country Liberal Government introduced an arrest, detain and fine regime for minor offences including indecent or obscene language, which it labelled 'paperless arrest' laws. ${ }^{18}$ These laws allow police to arrest and hold a person for up to four hours in custody (or up to twelve hours if intoxicated) without charge, before issuing the person an infringement notice. ${ }^{19}$ Indigenous Australians, whose language

14 Police v Pfeifer (1997) 68 SASR 285; Pregelj v Manison (1987) 51 NTR 1; Luke McNamara and Julia Quilter, 'Time to Define the Cornerstone of Public Order Legislation: The Elements of Offensive Conduct and Language under the Summary Offences Act 1988 (NSW)' (2013) 36(2) University of New South Wales Law Journal 534.

15 McNamara and Quilter have also argued that authorities on the issue in the Northern Territory and South Australia tend to embark on a global inquiry as to whether a single mens rea state must be proven for offensive language and conduct charges, as opposed to asking whether a fault element attaches to each of the actus reus components. See Luke McNamara and Julia Quilter, above n 14; Luke McNamara and Julia Quilter, "Turning the Spotlight on "Offensiveness" as a Basis for Criminal Liability' (2014) 39 Alternative Law Journal 36; Jeffs v Graham (1987) 8 NSWLR 292.

16 SO Act s 4A; Criminal Code (WA) s 74A; Crimes Act 1900 (ACT) s 392.

17 Criminal Procedure Act 1986 (NSW) ss 333-337; Criminal Procedure Regulation 2010 (NSW) cl 10, Sch 3; Penalties and Sentences Act 1992 (Qld) s 5; Police Powers and Responsibilities Act 2000 (Qld) s 394; State Penalties Enforcement Act 1999 (Qld) Sch 2; Police Offences Act 1935 (Tas) s 61; Monetary Penalties Enforcement Act 2005 (Tas) s 14; Summary Offences Act 1966 (Vic) ss 60AA, 60AB(2); Criminal Code (WA) ss 720-723; Criminal Code (Infringement Notices) Regulations 2015 (WA) Sch 1; Summary Offences Regulations 1994 (NT) regs 3-4A. See also Elyse Methven, 'A Very Expensive Lesson: Counting the Costs of Penalty Notice for Anti-Social Behaviour' (2014) 26 Current Issues in Criminal Justice 249; Tamara Walsh, 'Won't Pay or Can't Pay-Exploring the Use of Fines as a Sentencing Alternative for Public Nuisance Type Offences in Queensland' (2005) 17 Current Issues in Criminal Justice 217.

18 Northern Territory, Parliamentary Debates, Legislative Assembly, 22 October 2014, 12th Assembly (Mr Elferink).

19 Police Administration Act (NT) ss 123, 133AB; Police Administration Regulations (NT) reg 19A. See also North Australian Aboriginal Justice Agency Ltd v Northern Territory (2015) 326 ALR 16. 
is disproportionately punished through offensive language fines and charges, ${ }^{20}$ comprise an estimated 80 per cent of those detained under the paperless arrest scheme. ${ }^{21}$

It is necessary for the purposes of this essay to highlight three additional matters. First, it is not written in legislation (Tasmania aside) ${ }^{22}$ that cursing or swearing amounts to offensive, indecent or obscene language. Despite this, police and judicial officers have historically used, and continue to use offensive language crimes to target swear words. ${ }^{23}$ Secondly, offensive language is a matter for 'judicial notice', meaning that a judicial officer (a magistrate or judge) must rely upon her 'common sense' and 'everyday experience' in determining whether language is offensive. ${ }^{24}$ As Johnson J stated in Heanes $v$ Herangi, in relation to a charge of disorderly conduct by using offensive language in public, 'Magistrates with a wide experience of life and human foibles are generally in the best position to judge whether conduct should be categorised as disorderly'. ${ }^{25}$ Expert evidence on questions of language and linguistics is deemed irrelevant and inadmissible to this assessment. ${ }^{26}$ Because of this, decision-makers may indiscriminately apply whichever linguistic or 'folk-linguistic'27 ideas they see fit to words when assessing their offensiveness. Finally, with

20 See, for example, NSW Ombudsman, Review of the Impact of Criminal Infringement Notices on Aboriginal Communities (2009); Rob White, 'Indigenous Young Australians, Criminal Justice and Offensive Language' (2002) 5 Journal of Youth Studies 21; Tamara Walsh, 'Who Is "Public" in a "Public Space”?' (2004) 29 Alternative Law Journal 81.

21 Human Rights Law Centre, High Court Upholds but Curtails Northern Territory's Paperless Arrest Laws (1 November 2015) <http://hrlc.org.au/ high-court-upholds-but-curtails-northern-territorys-paperless-arrest-laws/>.

22 Police Offences Act 1935 (Tas) s 12, prohibits, inter alia, 'cursing' or 'swearing' in any public place, or within the hearing of any person in that place.

23 When comprehensive obscene language provisions were first introduced under the Vagrancy Act 1849 (NSW), police and magistrates commonly chastised the use of the words bastard, bloody, bugger, whore or hell in a public place. Now, police use offensive language to primarily target the words fuck (and its derivatives), cunt or a combination of both, cited in Michael Sturma, Vice in a Vicious Society (University of Queensland Press, 1983); NSW Ombudsman, above n 20; Jo Lennan, 'The Development of Offensive Language Laws in NineteenthCentury New South Wales' (2007) 18 Current Issues in Criminal Justice 449; Brian Taylor, 'Offensive Language: A Linguistic and Sociolinguistic Perspective' in Diana Eades (ed), Language in Evidence: Issues Confronting Aboriginal and Multicultural Australia (University of New South Wales Press, 1995) 219.

24 Dalton v Bartlett (1972) 3 SASR 549; Romeyko v Samuels (1972) 2 SASR 529; Hortin v Rowbottom (1993) 68 A Crim R 381; Del Vecchio v Couchy [2002] QCA 9; Heanes v Herangi (2007) 175 Crim R 175.

25 Heanes v Herangi (2007) 175 Crim R 175, 218; citing Mogridge v Foster [1999] WASCA 177, [7]-[8] (McKechnie J).

26 Dalton v Bartlett (1972) 3 SASR 549; Romeyko v Samuels (1972) 2 SASR 529; Hortin v Rowbottom (1993) 68 A Crim R 381.

27 The expression 'folk linguistic theories' is often used in linguistics to express the same idea encapsulated by the term language ideologies: Ruth Wajnryb, Expletive Deleted: A Good Look at Bad Language (Simon and Schuster, 2005) 108-109. 
the increasing use of CINs, police officers are regularly the witnesses to, 'victims', and arbitrators of offensive language. Accordingly, it is often the addressees of the language - police - who must adjudicate its offensiveness. When issuing CINs, police need not provide written reasons detailing how they applied the legal elements of offensive language crimes, shielding their interpretative reasoning from critique.

\section{LANGUAGE IDEOLOGIES}

Language ideologies are tacit judgments about how language works. ${ }^{28}$ Despite often being represented as natural or common sense, language ideologies are socially, culturally and historically conditioned. ${ }^{29}$ The impact of language ideologies extends beyond language; they also 'serve to rationalize existing social structures, relationships and dominant linguistic habits'. ${ }^{30}$ These 'common sense' ideas are harboured before, or in spite of, evidence being gathered. ${ }^{31}$ They are developed not through empirical evaluation, thoughtful research or intellectual debate, but are instead built 'layer upon layer, through constant repetition by popular and authoritative sources of a number of questionable views and assumptions which have assumed the status of a set of givens'. ${ }^{32}$ These ideologies thrive through repetition that makes it difficult to undo the 'truth' that they create. Importantly, people do not have equal access to creating and naturalising common sense ideas about offensive language in the criminal law. Instead, "primary definers ${ }^{33}$ in criminal justice debates, including judges, magistrates, attorneys-general, lawyers, academics, media commentators, police, police ministers and police unions leaders, play a critical role in constructing and reproducing ideas about offensive language. ${ }^{34}$

\section{Swear Words}

I use the term 'swear words', 'curse words' or 'four-letter words' interchangeably, to refer to a number of terms that have been socially tabooed. The word taboo, deriving from the Tongan term tabu, refers to

28 See, for example, Diana Eades, above n 5, 241.

29 Jan Blommaert, Discourse: A Critical Introduction (Cambridge University Press, 2005) 253.

30 Diana Eades, above n 5, 242.

31 Criminologists and criminal law scholars have also recognised that the language of 'common sense' is part of the persuasive rhetorical arsenal of the 'uncivil politics of law and order'. See Russell Hogg and David Brown, Rethinking Law and Order (Pluto Press, 1998) 19.

32 Ibid, 18.

33 Ibid, 18-19.

34 Diana Eades, Courtroom Talk and Neocolonial Control (Walter de Gruyter, 2008) 35. 
a 'ban or inhibition resulting from social custom or aversion'. ${ }^{35}$ Virtually all societies retain some taboos against the use of certain words. ${ }^{36} \mathrm{As}$ they are ever-changing it is impossible to delimit a stable list of swear words. However, swear words have a number of properties in common. They are generally used figuratively; in other words, they are not interpreted literally (although they can be), and are mostly restricted to colloquial styles of language. ${ }^{37}$ Swear words have a variety of functions; they can be used for catharsis or pain-relief, as non-violent expressions of resistance, to express anger, to add emphasis, to deride, to express humour, as a social lubricant or as a social leveller. ${ }^{38}$ Above all, curse words function as an essential emotional component of speech; '[t]hey intensify emotional expression in a manner that is not possible with non-curse words'. ${ }^{39}$

Linguists have identified a number of ways to recognise swear words, including by looking at how people use euphemisms in substitute for 'unmentionable' terms (such as the use of shoot or sugar instead of shit) or other avoidance strategies (such as 'the f-word' or 'c---'). ${ }^{40}$ One can also locate the coprolalia (uncontrollable swearing) of those who have Tourette's Syndrome, who tend to shout the most inappropriate words in their language. ${ }^{41}$

Swear words can also be distinguished from other words in the English language by identifying their semantic range. Swear words may refer to sexual organs and activities (for example, cunt, dickhead or wanker); religious figures or beliefs (for example, Damn it or Jesus Christ); scatological objects or ideas (for example, shit, piss or bloody); animal names (for example, cow, bitch or dog); ancestral allusions (for example, son of a bitch or bastard); or constitute offensive slang (for example, cluster fuck). ${ }^{42}$ My analysis in this essay is confined to these particular semantic fields. I do not consider judicial language ideologies in relation to ethnic, racial or other discriminatory slurs (for example, nigger or faggot) or words that

35 Timothy Jay, 'The Utility and Ubiquity of Taboo Words' (2009) 4 Perspectives on Psychological Science 153, 153 citing The American Heritage Dictionary of the English Language (Houghton Mifflin, 2000); Kate Burridge, 'Linguistic Cleanliness is Next to Godliness: Taboo and Purism' (2010) 26 English Today 3.

36 Geoffrey Hughes, Swearing: A Social History of Foul Language, Oaths and Profanity in English (Blackwell, 1991) 8-9.

37 Keith Allan and Kate Burridge, Forbidden Words: Taboo and the Censoring of Language (Cambridge University Press, 2006) 75.

38 Richard Stephens and Claudia Umland, 'Swearing as a Response to Pain - Effect of Daily Swearing Frequency' (2011) 12 The Journal of Pain 1274; Wajnryb, above n 27; Jay, above n 35.

39 Timothy Jay, Why We Curse: A Neuro-Psycho-Social Theory of Speech (John Benjamins, 1999) 16-17.

40 Keith Allan and Kate Burridge, Forbidden Words: Taboo and the Censoring of Language (Cambridge University Press, 2006); Luke Fleming and Michael Lempert, 'Introduction: Beyond Bad Words' (2011) 84 Anthropological Quarterly $5,5-6$.

41 Jay, above n $35,154$.

42 Ibid. 
refer to perceived physical, psychological or social deviations (for example, retard or loser).

\section{Language Ideologies And Swearing}

Language ideologies about swearing flourish in legal, media, political and everyday discourse on swearing. As linguist Ruth Wajnryb has written, 'it's a topic on which everyone seems to have a viewpoint'. ${ }^{43}$ Language ideologies about swear words are typically negative, aesthetically judgmental, sometimes inflammatory, and create or presuppose harms caused by swearing. ${ }^{44}$ Popular views include that swear words:

- are becoming increasingly pervasive in society;

- $\quad$ are indicative of 'slipping' standards;

- are more disgusting than those used in the past;

- $\quad$ are 'the linguistic crutch' of people with a lazy mind;

- $\quad$ are used by those who have 'loose' morals, particularly in relation to sex;

- demonstrate a lack of control; and

- challenge or disrespect authority. ${ }^{45}$

One reason why language ideologies inform everyday understandings of swear words is because these so-called 'dirty words' have long been considered an inappropriate or illegitimate topic for scholarly examination; swear words are too dirty for many academics to sully their hands with. ${ }^{46}$ Fortunately, a small but growing number of linguists, anthropologists, psychologists and English language historians have examined the phenomenon of swearing. I engage this body of research to interrogate judicial language ideologies in offensive language cases. ${ }^{47}$

43 Wajnryb, above n 27, 7.

44 Ibid; see also Jay, above n 39; Melissa Mohr, Holy Shit (Oxford University Press, 2013); Tony McEnery, Swearing in English: Bad Language, Purity and Power from 1586 to the Present (Routledge, 2004).

45 Mohr points to James O'Connor's book, Cuss Control: The Complete Book of How to Curb Your Cursing (Three Rivers Press, 2000) as encapsulating this common sense attitude towards swearing including that swearing is wrong because 'it shows you don't have control', 'it discloses a lack of character', 'it's abrasive, lazy language' and 'it lacks imagination' cited in Mohr, above n 44, 13, 18. See also Fleming and Lempert, above $\mathrm{n}$ 40; Kristin L Jay and Timothy B Jay, 'Taboo Word Fluency and Knowledge of Slurs and General Pejoratives: Deconstructing the Poverty-of-Vocabulary Myth' (2015) 52 Language Sciences 251; Edwin L Battistella, Bad Language: Are Some Words Better than Others? (Oxford University Press, 2005).

46 Jay, above n 39, 10.

47 Hughes, above n 36; Geoffrey Hughes, An Encyclopedia of Swearing: The Social History of Oaths, Profanity, Foul Language, and Ethnic Slurs in the EnglishSpeaking World (Routledge, 2015); Jay, above n 39; Jay and Jay, above n 45; McEnery, above n 44; Allan and Burridge, above n 40; Burridge, above n 35; Steven Pinker, The Stuff of Thought: Language as a Window into Human Nature (Viking Penguin, 2007); Mohr, above n 44; Fleming and Lempert, above n 40; Wajnryb, above n 27. 


\section{Language Ideologies in Offensive Language Cases}

In this part I examine two interrelated language ideologies expressed in the cases Jolly $v$ The Queen and Heanes $v$ Herangi. The first language ideology is an example of what Eades has termed the 'ideology of literalism': whereby judicial officers (selectively) interpret words by reference to their literal or dictionary meaning(s), and exclude other more probable contextual meanings. ${ }^{48}$ The second ideology can be regarded as a sub-set of this ideology of literalism, being the notion that some words necessarily have a sexual connotation, irrespective of how they are used. Both ideologies are premised on a 'referential' conception of language, where language is seen as 'essentially a transparent and objective medium of communication'. ${ }^{49}$ This referential view is in sharp contrast to a sociolinguistic theory of language, which underscores the contextual situatedness of language, conceiving language as a 'non-neutral medium'50 or a 'tool [that] is 'socially created, manipulated, and changed'. ${ }^{51}$

As outlined above, in Jolly $v$ The Queen, Cogswell DCJ ultimately found that Jolly's words amounted to offensive language, stating that when Jolly 'went on to make references to members of the police officers' families having sexual relations with each other' this no longer allowed Mr Jolly a defence under the section. Cogswell DCJ further stated: 'I have the same view about the reference to animals in the expression "Dog cunts". The images conjured up by such language are obviously - in my opinion - very offensive to anyone who might overhear them. ${ }^{52}$

These extracts are examples of recontextualisation. ${ }^{53}$ When judges, police officers, witnesses, and so on talk or write about offensive language, they recontextualise the language and the context in which it was used by reallocating roles, rearranging the social relations between the participants, reordering the events and reframing the context. ${ }^{54}$ Recontextualisations can add detail, transform persons and events, eliminate detail or shift focus. ${ }^{55}$ In the present example, Cogswell DCJ transformed the facts of

$48 \quad$ Eades, above n 5, 245-247.

49 Janet Ainsworth, 'You Have the Right to Remain Silent ... But Only If You Ask for it Just So: The Role of Linguistic Ideology in American Police Interrogation Law' (2008) 15 International Journal of Speech, Language and the Law 16 (citations omitted).

50 Alessandro Duranti, 'Linguistic Anthropology: The Study of Language as a Non-Neutral Medium' in Rajend Mesthrie (ed), The Cambridge Handbook of Sociolinguistics (Cambridge University Press, 2011).

51 Diana Eades, 'Theorising Language in Sociolinguistics and the Law' in Nik Coupland (ed), Sociolinguistics: Theoretical Debates (Cambridge University Press, 2016) (forthcoming) 368.

52 It is difficult to know from this statement whether Cogswell DCJ considered that the invocation of the families of police having sexual relations with each other crossed the line. If he had been just talking about the officers themselves, would Jolly have had the defence of reasonable excuse available?

53 See, for example, van Leeuwen, above n 6, 12-17.

54 Ibid, 13.

55 Ibid, vii-viii. 
Jolly's case by substituting the words used by Jolly - the noun phrase 'dog cunts' and the sentence, 'You fucked his mum and he fucked your mum and he fucked his mum and his sister and your brother and son' - with the judge's subjective interpretations of the words as 'references to members of the police officers' families having sexual relations with each other', 'the reference to animals' and 'the images conjured up by such language'. ${ }^{56}$ In construing Jolly's language in this way, Cogswell DCJ focused on the literal or surface meanings of the defendant's words, rejecting alternative contextual interpretations that might construe the words as slurs somewhat divorced from their dictionary definitions.

It is instructive to analyse Cogswell DCJ's construction of agency and cause and effect (or causality) in his interpretation of Jolly's words. Fairclough has explained that an analysis of causality involves interrogating who (or what) is represented as doing what to whom, and how. ${ }^{57}$ The clause, 'The images conjured up by such language' is a transactive action in the passive voice, involving two participants: the actor - the one who does the deed, and the goal - the one to which the process is extended. ${ }^{58}$ In the clause, 'The images conjured up by such language', the abstract noun 'such language' is the actor, 'the images' are the goal, and the verb or the process is 'to conjure up'. Through this grammatical construction of cause and effect, Cogswell DCJ attributed power or causality to the abstract noun 'such language', which is represented as magically conjuring up 'the images' of dog cunts. Further, the judge's use of the definite article, 'the' in '[t]he images conjured up by such language' and 'the reference to animals in the expression "Dog cunts" (as opposed to the indefinite article equivalents, such as 'images conjured up by such language'), is ideologically important, in that the definite article can trigger presuppositions: propositions that are deemed common ground, or already in existence. Critical linguist Hillary Janks has argued that we should be attentive to the persuasive effect of a word as 'seemingly innocuous' as 'the':

The use of the definite article presupposes shared knowledge. It is therefore used to refer to established information, whereas the indefinite article is used to refer to new information. So, for example, referring to 'weapons of mass destruction' as 'the weapons of mass destruction' presupposes both that we all know what weapons we are talking about and that they exist. ${ }^{59}$

Applying these observations to the views of Cogswell DCJ, we see that his Honour represented as already established the fact that Jolly was referring to animals when he used the expression 'dog cunts'. Similarly, Cogswell DCJ presupposed that the words 'dog cunts' conjure up images. The judge attributed to swear words a kind of agency in which these words axiomatically, without human intervention, generate images of animals'

$56 \quad$ Ibid, 17.

57 Fairclough, above n 6, 51.

58 Van Leeuwen, above n 6, 60; Hilary Janks, 'Language and the Design of Texts' (2005) 4 English Teaching 97, 107. 
anatomy. Cogswell DCJ did not mention that humans must exercise their imaginations (as Cogswell DCJ himself did) to conjure up these images.

It could be argued that Jolly's phrase 'fucking dog cunts' was not intended to, and in many minds may not evoke images of dogs' sexual organs. (Indeed, many people could not readily conjure up such images). ${ }^{60}$ His choice to construe the words 'dog cunts' in a denotative way is artificial, if not absurd. The judge has made what Wajnyrb has identified as a common error when interpreting swear words; he has "tried to define CUNT as one might, say, "chair" or "physics" or "collective consciousness". It just doesn't work.' 61 As Wajnryb has explained, one reason why this 'doesn't work' is because swear words are 'overly invested in connotative or emotional associations rather than descriptive or dictionary meanings' ${ }^{62}$ One cannot simply read the entry of swear words in the Oxford English Dictionary to find their meanings in all uses; one must turn to the 'context' of their use. ${ }^{63}$ Cogswell DCJ's application of the 'ideology of literalism' overshadows the availability of alternative and perhaps more credible contextual interpretations of Jolly's words (noting that 'the context' of a case is selectively represented through recontextualisation) ${ }^{64}$ including that Jolly was using the phrase 'fucking dog cunts' as a pejorative, with the words fucking and cunts added for 'intense emotional effect', ${ }^{65}$ and the word dogs used in the sense of a common insult to denote police officers. ${ }^{66}$ Furthermore, it could be argued that Jolly used the words, 'You fucked his mum and he fucked your mum and he fucked his mum ...', to mimic provocative schoolyard or street swearing referred to as 'flyting', or in African American contexts as 'playing the dozens': verbal contests involving 'highly inventive figurative language, in which the taunts subject the participants, their close relatives, and selected parts of their bodies to an increasingly bizarre set of unpleasant circumstances' ${ }^{67}$ As offensive language is a matter for 'judicial notice', Cogswell DCJ was either not

$60 \quad$ Stutsel v Reid (1990) 20 NSWLR 661 provides another example of where it would be absurd to construe swear words literally. In that case, the respondent, Brian John Reid, said to police officers on Anson St, Bourke at 1.15am on 10 February 1990, 'Why don't you fuck off you dog arse cunts?' Similarly, the appellant in Couchy v Guthrie [2005] QDC 350 yelled a number of phrases towards a man in a garage area beneath a boarding house, open to, and in view of, Gibbon Street, Woolloongabba, including: 'Hey, I'll fucking kill that dog cunt'; 'He's just a fucking cunt. A dog. I will fucking kill him'.

61 Wajnryb, above n 27, 69.

62 Ibid.

63 Ibid.

64 Blommaert, above n 29, 40.

65 Wajnryb, above n 27, 70.

66 For example, it was argued that the primary trigger for Cameron Doomadgee's arrest and subsequent death on Palm Island was Doomadgee's singing of the 'one-hit-wonder' by the Baha Men 'Who let the dogs out ... Woof, woof, woof, woof, woof', to which Senior Sergeant Christopher Hurley took offence. Chloe Hooper, The Tall Man: Death and Life on Palm Island (Random House, 2010).

67 David Crystal, The Encyclopedia of the English Language (Cambridge University Press, 1995) 401 (emphasis added); Hughes, above n 36, 47-50. 
privy to, or could overlook such interpretations in favour of judicial 'common sense' understandings of how language works.

Another case in which a judicial officer proffered a number of language ideologies in relation to swear words, many of which are inconsistent with linguistic research, is the Supreme Court of Western Australian case Heanes $v$ Herangi, concerning an appeal against a conviction of disorderly conduct by using offensive language. In that case, Johnson $\mathrm{J}$ found that the word fuck is only used by 'a section of society', that swear words are akin to physical violence, ${ }^{68}$ and that "words which ordinary decent-minded people may consider acceptable if spoken in private in very limited circumstances, may not be considered acceptable if said in public or to an authority figure or in the presence of children' ${ }^{69}$ For the purposes of this essay however, I will interrogate Johnson J's assertions, analogous to those of Cogswell DCJ, that swear words have an 'objective nature' and that some swear words will 'have a sexual connotation, irrespective of whether they are being used in that sense'. ${ }^{70}$

The belief that swear words have a 'nature' or necessarily have a sexual connotation, irrespective of use, has been disputed by linguistic literature on taboo words and swearing. To assert that swear words have an 'objective nature' is to deny that humans attach meanings to words, being 'sounds heard, sequences of symbols on a page, abstract language constituents' ${ }^{71}$ through social usage. Like Wajnryb (see above), linguists Keith Allan and Kate Burridge remind us that the 'connotation' of a word means 'its semantic effects (nuances of meaning) that arise from encyclopedic knowledge about the word's denotation and also from experience, beliefs and prejudices about the contexts in which the word is typically used', ${ }^{72}$ while psychologist and linguist Steven Pinker has described connotations as an 'emotional colouring distinct from what the word literally refers to'. ${ }^{73}$ Connotations change depending on context, including 'smaller' contexts such as a word's 'textual context' to infinitely big contexts, including the nation or the historical period in which words were used. ${ }^{74}$ For example, the meaning of the word fuck changes depending on its textual context: it can be substituted for other swear words, such as hell or bloody (for example, 'Fucking fantastic' can be interchanged with 'Bloody fantastic'); it can be used as a noun (as in 'You're a lazy fuck'); as a verb ('to fuck someone over'); as an adjective ('This engine's fucked'); or as an adverb ('You know fucking well what I mean' or 'unfuckingbelievable'). ${ }^{75}$ In each

68 Heanes v Herangi (2007) 175 Crim R 175, 219, citing Heydon J in Coleman v Power (2004) 220 CLR 1.

69 Heanes v Herangi (2007) 175 Crim R 175, 205, 212.

70 Ibid.

71 Ibid, 40.

72 Allan and Burridge, above n 40, 31.

73 Pinker, above n 47, 331.

74 Blommaert, above n 29, 40.

75 Christopher Fairman, 'Fuck' (2006) 28 Cardozo Law Review 1711, 1719-1720 fn 56 . 
of these examples the word fuck is used in a distinct sense and is void of any inherent, including sexual, meaning.

A further assumption inherent in both Cogswell DCJ's and Johnson J's language ideologies is that swear words warrant criminal sanction because they allude to sexual acts or body parts. It is unlikely that the judges would have perceived an exclamation such as, 'I had sex last night,' if uttered aloud in a public place, as criminally offensive. It is similarly unlikely that this statement, being void of swear words, would attract police attention. As Henry Hitchings has observed, '[f]ar fewer people will be upset by the word vagina than will be appalled to hear the word cunt' ${ }^{76}$ This brings us back to the observation made at the start of this essay: that many politicians, police, judicial officers and members of the general public presume that offensive language crimes should target swear words. By singling out swear words as deserving criminal punishment, the law has naturalised the idea that swear words per se are intrinsically dirty, irrespective of human interpretation or contextual usage. Such a conception ignores sociolinguistic arguments that swear words are, as Burridge has argued, 'weeds of our own making'. ${ }^{77}$ Burridge has used this metaphor to illustrate her argument that words, like gardens, are contingent on human interpretation and context:

One speaker's noxious weed can be another's garden ornamental. A linguistic weed today can be a prized garden contributor tomorrow. Whether they are in gardens or in languages, weeds are totally centered around human value judgements. ${ }^{78}$

Swear words, like other words in the English language, do not have a nature; they are neither inherently good nor inherently bad, and they are not inherently sexual. Their taboo status is created and attached by humans, and this taboo will inevitably fade away.

\section{CONCLUSION}

Burridge's metaphor of words as 'weeds of our own making' reminds us that judicial officers need not construe swears words as 'bad' words. A magistrate might choose, as Magistrate Heilpern did in Police v Butler, ${ }^{79}$ to repeat the word fuck fifty-four times in their judgment, de-sensitising or 'numbing' their audience to any shock value the word might otherwise have had. They might describe the social uses of swear words in quotidian terms, replicating Magistrate Heilpern's description of 'private school uniformed kids (girls and boys) yell[ing] "fuck off" to each other across platforms' or his observation that '[i]f your children like JJJ and listen to it in the morning, one cannot help be assailed by the word "fuck" with

76 Henry Hitchings, The Language Wars: A History of Proper English (John Murray, 2011) 241.

77 Kate Burridge, Weeds in the Garden of Words (ABC Books, 2004) 8.

78 Kate Burridge, 'Taboo, Verbal Hygiene - and Gardens' (2010) 47 Idiom 17, 22.

79 [2003] NSWLC 2. 
regularity between mouthfuls of toast'. ${ }^{80}$ Alternatively, a judge might argue, as Rowland J did in Keft $v$ Fraser, that the word fuck:

[I]s a well known word whether used as a noun, adjective or verb. It has been known for two or three centuries and it has been used by some eminent writers. One hears it being used by people of both sexes and various ages. More often than not, when used either alone or in combination with other words, it does not bear its primary meaning ... Increasing use, of course, tends to lessen the impact. ${ }^{81}$

In these examples, swear words are not depicted as inherently dirty, but are attributed a place in ordinary human communication. Not only are these judges' views more consistent with sociolinguistic research on swearing, they also illustrate how, with offensive language deemed a matter for judicial notice, judicial officers can apply entirely contradictory ideas when adjudicating offensiveness. They can depict curse words as foul, fair or entirely unremarkable.

Offensive language crimes, as they are currently framed and applied, allow legal decision-makers to be inoculated from critique by linguistic experts. This in turn enables adjudicators to generate and apply 'common sense' ideas about language, including that swear words have an inherent nature and transmit referential meaning. Language ideologies that construct swear words as 'bad' words foster the idea that swear words, as opposed to other words in the English language, are an obvious and inevitable target of offensive language crimes. And many of these judicial language ideologies are contrary to sociolinguistic views of language, in which language is regarded as a non-neutral medium of communication that changes depending on context of use, and curse words in particular are seen as an integral and ubiquitous component of human speech. Sociolinguistic research thus offers a valuable perspective to expose problematic aspects of language interpretation in the area of offensive language crimes. 